Article

\title{
Bridging Academics' Roles in Knowledge Diffusion in Sustainability-Driven Public-Private Partnerships: A Case Study of the SDGs Workshop in Central Japan
}

\author{
Hoe Chin Goi *(D), Muhammad Mohsin Hakeem (D) and Frendy
}

check for updates

Citation: Goi, H.C.; Hakeem, M.M.;

Frendy. Bridging Academics'

Roles in Knowledge Diffusion in

Sustainability-Driven Public-Private

Partnerships: A Case Study of the

SDGs Workshop in Central Japan.

Sustainability 2022, 14, 2378. https:/ /

doi.org/10.3390/su14042378

Academic Editors: Yuzhuo Cai and Lili-Ann Wolff

Received: 15 December 2021

Accepted: 14 February 2022

Published: 18 February 2022

Publisher's Note: MDPI stays neutral with regard to jurisdictional claims in published maps and institutional affiliations.

Copyright: (C) 2022 by the authors. Licensee MDPI, Basel, Switzerland. This article is an open access article distributed under the terms and conditions of the Creative Commons Attribution (CC BY) license (https:/ / creativecommons.org/licenses/by/ $4.0 /)$.
NUCB Business School, Nagoya University of Commerce and Business, 1 Chome-3-1 Nishiki, Naka Ward, Nagoya 460-0003, Japan; hakeem_mm@gsm.nucba.ac.jp (M.M.H.); frendy_f@gsm.nucba.ac.jp (F.)

* Correspondence: goi_hc@gsm.nucba.ac.jp; Tel.: +81-52-203-8111

\begin{abstract}
This article discusses the role of academics in knowledge diffusion among various stakeholders using a case study of a sustainability-oriented workshop to address issues of a local forest in central Japan. This research employs thematic analysis through interpreted data from documents, minutes of meetings, workshop interactions among stakeholders, debriefing sessions, questionnaires, and fieldwork findings of participants in a regional business school. The findings show that Bridging Academics (BAs) have effectively facilitated knowledge diffusion amongst global, national and local stakeholder clusters. The interactions among workshop stakeholders resulted in outcomes that enhanced awareness of knowledge gaps, fostered effective communication, enabled knowledge extension, and created shared values. The study contributes towards the understanding of academics' roles in collaborative settings for sustainability and suggests a multi-node knowledge link model as a collaborative mechanism for knowledge diffusion. The study suggests implications for stakeholders and provides a use case relevant to sustainability-based regional development.
\end{abstract}

Keywords: bridging academics; regional sustainability; knowledge diffusion; public-private partnership; multi-node knowledge link model; stakeholders

\section{Introduction}

Sustainability is defined as fulfilling the needs of the present without compromising the ability of future generations to meet their own needs [1]. As sustainable development accounts for the needs of all members of a given society, the creation and dissemination of knowledge related to sustainability are expected to involve partnerships with the widest range of stakeholders possible. Stakeholders are drivers of organizational change when they have access to channels for participation and leadership [2]. A higher education institution is well-positioned to become a knowledge hub in a given region by providing channels through which stakeholders can engage in action-based projects on sustainability knowledge creation and dissemination, with the aim of better understanding the role of external stakeholders.

Empirical research results have indicated that isolated stakeholders cannot identify sustainable solutions to regional issues by themselves [3]. Therefore, a collaborative mechanism among universities and different stakeholders could contribute to economic development and knowledge advancement in the region. The relationship between universities and industries will especially enhance economic gains through the dissemination of knowledge and innovative solutions at the regional level $[4,5]$.

As institutions of higher education, universities are responsible for promoting economic and social development, particularly in the region where it operates. Through joint research projects and interactions, academics as a member of the higher education institution could have a role in facilitating collaborative arrangements. The term "bridging academics" (BAs) was introduced by Trippl [6] as a scholar who linked global and regional 
knowledge communities through networking. Such collaborative arrangements can be relevant in enabling sustainability-oriented projects to stakeholders' benefit in different regional settings.

This study employs the qualitative case-study approach of the Sustainable Development Goals (SDGs) Workshop. The workshop is a BAs-led multi-stakeholders collaboration, initiated by faculty members of Nagoya University of Commerce and Business (NUCB) Business School in the Chubu region of Japan. The region's economy accounts for $20 \%$ of Japan's shipment values of manufactured products and comprises approximately $10 \%$ of Japan's area, population, and gross regional production [7]. The emphasis on industrial growth that has characterized the development of this region has led to increased pressure on achieving sustainability-related goals.

The SDGs workshop took place in the Ricoh Ena Forest in the Ena City within the Tokai subregion of Chubu, Japan. The stakeholders of the workshop were invited to interact, collaborate, discuss issues, and consider future developments as well as present potential solutions pertaining to the Ricoh Ena Forest. The workshop stakeholders included Ricoh Corporation (Head Office) representatives, the Ricoh Ena Forest Management Committee, Ena City government representatives, Ena City International Exchange Association representatives (a local NPO), international students (NUCB Business School, Nagoya), and a researcher (Keio University, Tokyo).

Our study analyzed the case of the SDGs workshop that enabled collaboration among stakeholders in a sustainability-oriented project. The collaborative initiative created a unique platform for knowledge diffusion among stakeholders, including industry partners, government representatives, community members, nonprofit organizations (NPOs), and international researchers and students. The interaction among stakeholders with BAs serving as mediators provided a novel structure for exploring sustainability-oriented publicprivate partnerships (PPPs) to propose innovative solutions and disseminate knowledge related to sustainability issues that are relevant to the region.

Although universities represent institutional knowledge hubs at the macro level, the concept of BAs explains how the mobility of academic scientists individually contributes to knowledge transfer and socioeconomic growth [6]. Atta-Owusu [8] explored the concept of BAs and investigated their collaborative activities, specifically exploring how BAs led collaborative projects that facilitated the flow of knowledge to peripheral regions. However, Owusu's model falls short of providing real prescriptions for supporting BAs.

Our study extends on Trippl [6] and Atta-Owusu [8] studies by investigating the ways in which BAs enable partnership among stakeholders at the global and regional levels in tackling sustainability challenges. We examined the structure and process of BAs that led to collaborative arrangements to better understand knowledge diffusion among stakeholders in sustainability-oriented PPPs.

The SDGs workshop was our main subject of analysis, and we focused on stakeholder understanding of sustainability as well as any knowledge gaps that were identified. This study aims to answer the following research questions:

- How do BAs facilitate partnership among stakeholders in addressing sustainability challenges?

- What are the outcomes of knowledge diffusion with sustainability-driven publicprivate partnerships?

In response to the first research question, this study explored the collaborative mechanism which could be considered as the multi-node knowledge link model. The model verified the roles of BAs in facilitating partnership among global, national, and local stakeholders in addressing sustainability challenges. Each stakeholder group possesses a unique understanding of the challenges and perspectives regarding sustainability issues. We find that the BAs play an essential role as the hub of knowledge diffusion which facilitates a more cooperative and free knowledge exchange among stakeholders. The study's response to the second research question is as follows. We find that throughout the SDGs workshop, the presence of BAs ensures that every participant attains the minimum level 
of required understanding through information sessions on concepts and applications. The outcomes of the workshop are manifested as focused and result-oriented discussions. The discussions enabled the knowledge flow in all directions, which resulted in every participant discovering and adapting accordingly. We find that the workshop represents an effective method in facilitating BAs-led knowledge diffusion in a multi-stakeholders sustainability project. The study contributes towards the understanding of academics' roles in collaborative settings for sustainability and suggests a multi-node knowledge link model as a collaborative mechanism for knowledge diffusion and discussion of societal impact of universities on regional/national innovation ecosystems from the academic perspectives.

The remainder of this paper is divided as follows. Section 2 examines the literature on knowledge diffusion, BAs, and sustainability-oriented PPPs. Section 3 presents the research design with the research method and introduction of the SDGs workshop's background and stakeholders. Section 4 presents the findings and discussions on how BAs collaborate with various stakeholders and the outcomes of knowledge sharing and value creation through the stakeholders' interactions. Section 5 provides conclusions to the research questions and discusses the implications and limitations of the study.

\section{Literature Review}

The goal of this paper is to examine the effects of Bridging Academics (BAs) on knowledge diffusion among stakeholders of a sustainability-driven public-private partnership. In the literature review section, we identified research gaps by reviewing extant literature on knowledge diffusion, role of bridging academics in knowledge diffusion, and public-private partnerships in the context of a sustainability related project.

\subsection{Understanding Knowledge Diffusion}

Developed economies have transitioned from economies driven by commodity and manufacturing to those driven by knowledge development, innovation, and commercialization [9]. Therefore, persistent knowledge creation and dissemination is necessary to maintain sustainable innovation among stakeholders involved in value-added processes. Cai, Ferrer, and Lastra [10] applied the concept of the innovation ecosystem to explain how actors in universities and other organizations are concerned with the diffusion of knowledge and their interdependent relations in cross-geographical contexts to generate shared values for sustainability.

Academics play an integral role in the efficient creation and dissemination of knowledge. They can leverage their capabilities to connect with different stakeholders, using their access to institutional and personal knowledge bases that are diversified in terms of geographical location and cultural background [11]. Lattu and Cai [12] identified that the diversification of academic work is one of the key tensions faced by academics amongst Finnish universities in driving sustainability. They explained that academics need sustainability-related competence and sufficient resources to fulfill the job responsibilities beyond academics from an organizational perspective. The affinity and mobility of academic scientists in various regions can enhance knowledge transfer and socioeconomic growth in respective regions, as explained by Trippl [6].

Atta-Owusu [8] extended Trippl's [6] knowledge link model to consider aspects beyond mobility. New aspects such as publications, research collaboration, social networks, cultural contexts, and global knowledge dispersion were considered. His study concluded that the development of collaborative projects and working with stakeholders can create prospects for continuous knowledge flows. The knowledge diffusion process can be enhanced by engaging external stakeholders in knowledge transfer.

However, Atta-Owusu's [8] quantitative data model did not provide applicable prescriptions for supporting BAs in other contexts. We believe that the model justified the role of BAs in knowledge diffusion but overlooked the development process and structure of collaborative arrangements. The limitation is understandable because the sample size was only large enough to focus on the peculiarities of a single collaborative project. In this 
study, we employed the proposed model in a single collaborative project by considering the engagement mechanism and differences among global and regional stakeholders during knowledge dissemination. As agents of knowledge diffusion, academics can initiate a new project involving researchers, capable students, and corporate stakeholders from different regions. In addition, academics can expand their ongoing projects in different regions to engage new collaborators and increase the chances of knowledge spillover.

\subsection{Role of Bridging Academics in Knowledge Diffusion}

The knowledge exchange facilitated by academics has multiple dimensions, as academics can be a part of regional and global networks simultaneously. Trippl [6] defines bridging academics (BAs) as academics connecting global and regional knowledge communities through their networking and collaboration activities.

BAs act as knowledge diffuser agents through two key mechanisms: knowledge mobility and outcome-based partnership [13]. The first requires that BAs and contributors mobilize their knowledge that extends beyond the physical sense. Knowledge transfer occurs as long as participants are able to access and share their knowledge. The second criterion implies that the relationship between the stakeholders and the BAs is intended to achieve a specific goal(s) that benefit all stakeholders involved. Through these two mechanisms, BAs can tap upon the consolidated global and regional knowledge pool and efficiently dispense it to enrich stakeholders' understanding and fill knowledge gaps.

However, prior BAs literature $[6,13]$ overlooked the distinction within the regional stakeholders. Thus, this study utilized the case study of a multi-stakeholders sustainability project to investigate the mechanism in which BAs enable collaboration among global and a subset of regional stakeholders (national and local) when tackling sustainability challenges.

\subsection{Public-Private Partnerships in a Sustainability Related Project}

The 2014 United Nations Educational, Scientific and Cultural Organization (UNESCO) World Conference on ESD (Education for Sustainable Development) published the 'AichiNagoya Declaration'. The aim was to encourage participants to transform themselves and the society in which they live by developing knowledge, skills, attitudes, competencies, and values [14] and provide a theoretical framework for ESD in which the knowledge link among multiple stakeholders in global and regional clusters is effectively mediated by BAs. The knowledge link connectivity established among the stakeholders in the model provides a template for collaboration among stakeholders in advancing knowledge related to sustainable development.

Cheng et al. [15] proposed a model of public partnership that involves a higher level of commitment among the stakeholders by considering the issues of sustainability and environmental impact in the relationship. To achieve this goal, the partnership model involves NPOs in addition to existing corporations and government stakeholders. Under this partnership model, the PPPs projects should observe principles of good corporate governance and provide adequate disclosure on environmental impact and implications to the public [16]. The partnership requires actions to minimize adverse impacts of infrastructure projects through pollution management and reduction efforts by project members. The partnership also promotes collaborative arrangements that aim to minimize environmental damage and manage environmentally friendly resources to benefit the broader community [17].

Prior literature on strategic PPPs establishes that several strategic shortcomings are generally observed in such partnerships [18]. First, stakeholders' interests are misaligned as they prioritize their institutional interests, which are not well communicated to other stakeholders. Second, there is no intermediary organization bridging the gaps between the stakeholders. These limitations suggest the need for BAs to develop a program that connects diverse global and regional stakeholders to pursue a particular goal. Thus, our study employed the case study of a sustainability-driven public-private partnership to examine the outcomes of knowledge diffusion. 


\section{Research Design}

\subsection{Research Method}

We employ a qualitative case study approach to examine a contemporary event in the context of its environment and stakeholders in depth [19]. The case study method is preferable when attempting to provide a comprehensive analysis of various processes, organizational characteristics, and/or stakeholder perspectives or experiences and offers a unique perspective when exploring stakeholder interactions in the knowledge diffusion process [20]. This method is commonly employed in the literature to explore the effectiveness of public-private partnerships projects [21,22]. Our paper analyzed and developed a conceptual understanding by empirically investigating a case study through an inductive reasoning process.

The SDGs workshop was developed to understand the scope and limitations of the sustainability-oriented Ricoh Ena Forest and designed as a field-based project to enable knowledge transfer between global and regional stakeholders. The workshop involved BAs facilitating close interactions among stakeholders including international students and researchers, Ricoh Group headquarters, Ricoh Elemex Forest Committee, Ena City government, and a nonprofit organization. Using the case study of the SDGs workshop, the BAs created a collaborative model to harness the expertise of stakeholders to enable knowledge diffusion and identify effective sustainability approaches.

The SDGs workshop has evolved into a long-term research partnership amongst the stakeholders. The SDGs workshop serves as a unique case that provides deep insights into a collaborative mechanism and outcomes of BAs-led knowledge diffusion based on the Asian context. It is a representative case for multi-stakeholders public and private partnerships that focus on knowledge diffusion and sustainability studies.

We gathered documents, meeting minutes, workshop materials, and questionnaires to record interactions with and among all participants throughout the duration of the workshop. The timeline of the workshop is presented in Table A1 in Appendix A. A code was assigned to each participant while considering their category and affiliated clusters, as shown in Table A2 in Appendix A. The collected data were analyzed using the thematic analysis approach $[8,23]$. Each author independently performed the thematic analysis process, and the results were consolidated to ensure the validity of the analysis. Transcribed documents were read, and relevant keywords were identified in each document. The collection of keywords was then sorted, and relevant keywords were collated and assigned to common themes that were named, defined, and reviewed. From these themes, the thematic analysis results of the case study data are summarized in the findings and discussion section.

\subsection{Case Study: SDGs Workshop}

\subsubsection{Background of the Workshop}

Academics from the NUCB Business School (based in the Tokai subregion of Japan) were tasked to develop the SDGs workshop, which aims to promote sustainability-based knowledge diffusion between the global participants and regional stakeholders involved in the Ricoh Ena Forest. The Ricoh Ena Forest is located in Ena City adjacent to Ricoh Elemex Corporation, a manufacturing subsidiary of Ricoh Corporation, which is well known for producing a variety of electronic equipment including photocopiers, optical devices, and cameras. Ena City is a small town with an estimated population of approximately 49,000 people as of January 2021. Since 2010, Ricoh has initiated forest conservation activities at the Ena forest [24] led by staff members from Ricoh Elemex Corporation with financial support from the corporate headquarters (HQ). Currently, the range of activities includes conservation of rare species in the forest by increasing environmental awareness among the young generation and the social and physical well-being of local residents.

The objective of the SDGs workshop was to help all participants improve their understanding of concepts regarding sustainability and share their knowledge based on the Ricoh Ena Forest. The workshop provided in-depth studies on the sustainability strategy 
of the Ricoh Ena Forest and how it aligned the mission of the SDGs specified by the United Nations. Collaboration between academics and stakeholders was achieved by undertaking three phases of the SDGs workshop: fieldwork planning, implementing workshops, and receiving feedback from stakeholders. The workshop aimed to employ the Ricoh Ena Forest to understand the development of sustainability, its business relevance, and enable knowledge transfer among different stakeholders. The planning, execution, and reflection sessions of the first workshop lasted for nine months, as specified in Table A1 of Appendix A.

The workshop was conducted virtually involving all participants and stakeholders interacting with each other in real-time over four separate sessions from September to December 2020. Each session lasted for four hours. International students were divided into four groups to tackle different sustainability problems. Each group was put together in a balanced manner with respect to academic background, nationality, and gender. The respective stakeholders participated online to present their organizational background and practices related to SDGs. They were also interviewed by the respective groups to give personal opinions and perceptions about the theme of sustainability for about four hours per session. A final presentation was given by the student groups to all the stakeholders, who in turn, provided feedback and consideration for the adoption of the given proposals.

\subsubsection{SDGs Workshop Stakeholders}

The workshop stakeholders were made up of representatives and participants from academia, industry, government, and society. The academic comprises seventeen international students enrolled in the MBA program at NUCB Business School and participated in the SDGs workshop. They were divided into four teams and tasked with investigating, evaluating, and making recommendations to improve outcomes for the Ricoh Ena Forest while considering the needs of the other stakeholders. In addition, one international researcher from Keio University with research expertise in the area of sustainable development participated in the workshop as well. None of the aforementioned academics had visited Ricoh Ena Forest or had any history of interaction with other stakeholders prior to the commencement of the SDGs workshop.

From the industry, two senior managers from the Ricoh Group HQ Sustainability Department represented the Ricoh Group. They provided key information about the group's mission, corporate strategy, and nationwide practices employed in sustainability projects within different parts of Japan. They also provided macro and strategic perspectives with respect to project rationality. The company provides financial support, in addition to central government grants for forest conservation and community-oriented activities. However, management at the Ricoh Group HQ did not directly intervene with sustainability outcomes, nor did they interact with the Ena City government or local residents. There were two delegates representing Ricoh Elemex Corporation. They represented the Forest Committee and shared knowledge about how they had organized activities and managed the Ricoh Ena Forest.

Three government officials from Ena City participated in the SDGs workshop; the representatives were in charge of planning, environment, and forestry. They were also responsible for initiating and reporting sustainability activities and outcomes performed by the municipal government.

Executive Director of Ena International Exchange Association (EIEA) who was responsible for sharing and providing feedback on behalf of local residents living near the Ricoh Ena Forest. The aforementioned groups of local stakeholders did not have any formal meeting to address sustainability issues or share knowledge with other stakeholders prior to the SDGs workshop. 


\section{Findings and Discussions}

\subsection{Collaborative Mechanism: Multi-Node Knowledge Link Model}

It is believed that stakeholders collaborating on a particular project may have a different understanding regarding the scope and limitations of the project due to lack of interaction. A mutual platform can reduce the knowledge gaps among the stakeholders by facilitating connectivity and collaboration. One participant explained the phenomenon:

It was very interesting to have the point of view of other stakeholders, the Ena city representatives, during this session. It was very necessary for us to see their side of the

Ricoh Ena Forest and the actions they are developing for the city. It made us understand better on what terms they agree to collaborate. (IS-12)

The literary paradigms are based on the stakeholder's separation into global and regional spheres. The SDGs workshop enabled us to explore the regional stakeholders in-depth while contemplating their views, understanding, and contribution towards the bigger picture. The differences in regional stakeholders were due to variations in the available information as well as interpretation expertise. Considering the geographical and knowledge-based context, we further categorized the regional stakeholders into two different clusters: national and local stakeholders. The geographical context here refers to stakeholders' factual location and the possibility of encompassing other stakeholders into their sphere of influence. Knowledge-based context refers to stakeholders' understanding, perception, and access to relevant information and their ability to evaluate its relevance in accordance with the ground realities.

National stakeholders are the individuals representing any organization with a nationwide knowledge and responsibility to meet sustainability goals in multiple regions. On the other hand, local stakeholders are the parties with a locality-focused knowledge and responsibility to meet sustainability goals within the same geographical region.

It was interesting to ask about the motivation of the stakeholders and why they are taking part in this project. It helped us understand a lot their mentality and the fact that philanthropy is a big part of their motivation in this project. (IS-7)

The above-mentioned statement uncovers the underlying assumption about the group of stakeholders collaborating in a sustainability-oriented setting. The collaboration reveals the differences in knowledge and understanding due to variations in their geographical and knowledge-based context. For global stakeholders, knowledge refers to the information, expertise and practices exercised to manage comparable projects across countries under various social and macroeconomic environments. Generally, global stakeholders include expatriate community members, global NPOs, multinational corporations, and international researchers who have the ability to offer different perspectives [25] and can explore and evaluate the project in ways that are not evident to regional stakeholders. SDGs workshop global cluster included NUCB Business School's MBA students (international students from different countries) and an international researcher from Keio University, Japan.

With a broader scope, the national stakeholders consider a particular project as a part of a bigger portfolio. Their knowledge of the project refers to a distinctive interpretation of information while considering the macro-level factors and objectives of the project to achieve certain goals within the desired timeframe. The national stakeholder cluster involves central government, national NPOs, and firms' headquarters (HQ). Representatives from Ricoh Corporation HQ were categorized as national stakeholders for the SDGs workshop. After interaction with Ricoh representatives, a student observed this:

... they are not only doing one or two projects, but it really seems like the RICOH itself uses SDG in many different areas of the company. (IS-3)

In contrast to the national stakeholders, the local stakeholders are focused on the locality and project's implications for the local community. Local stakeholders comprise the local government, the firm's local office, community members, and local NPOs. These stakeholders are familiar with the local environment, practices, and ground realities. Their 
direct exposure provides them with better local knowledge and equips this group among others in facing and resolving issues concerning the project [26]. We categorized Ricoh Ena Forest Management Committee, Ena City Government, and a nonprofit organization as local stakeholders of the SDGs workshop.

Prior to the commencement of the SDGs workshop, all stakeholders across the three clusters, global, national, and local, had no common platform to interact and exchange information regarding project objectives and wider implications for the community focusing on sustainability. Thus, the academics which we refer to as Bridging Academics (BAs) provided a formal sustainability-oriented platform for interaction and knowledge diffusion. The SDGs workshop acted as a collaborative platform for all stakeholders where the collaborative mechanism evolved into different tiers of interaction.

The distribution of stakeholders and the evolution of interaction mechanisms can be represented as a multi-node knowledge link model (Figure 1). The model explains the pivotal role of academics in linking stakeholders with each other while considering their geographical and knowledge-based context. In the multi-node knowledge link model, bridging academics plays a vital role in facilitating knowledge diffusion in a participatory and collaborative environment.

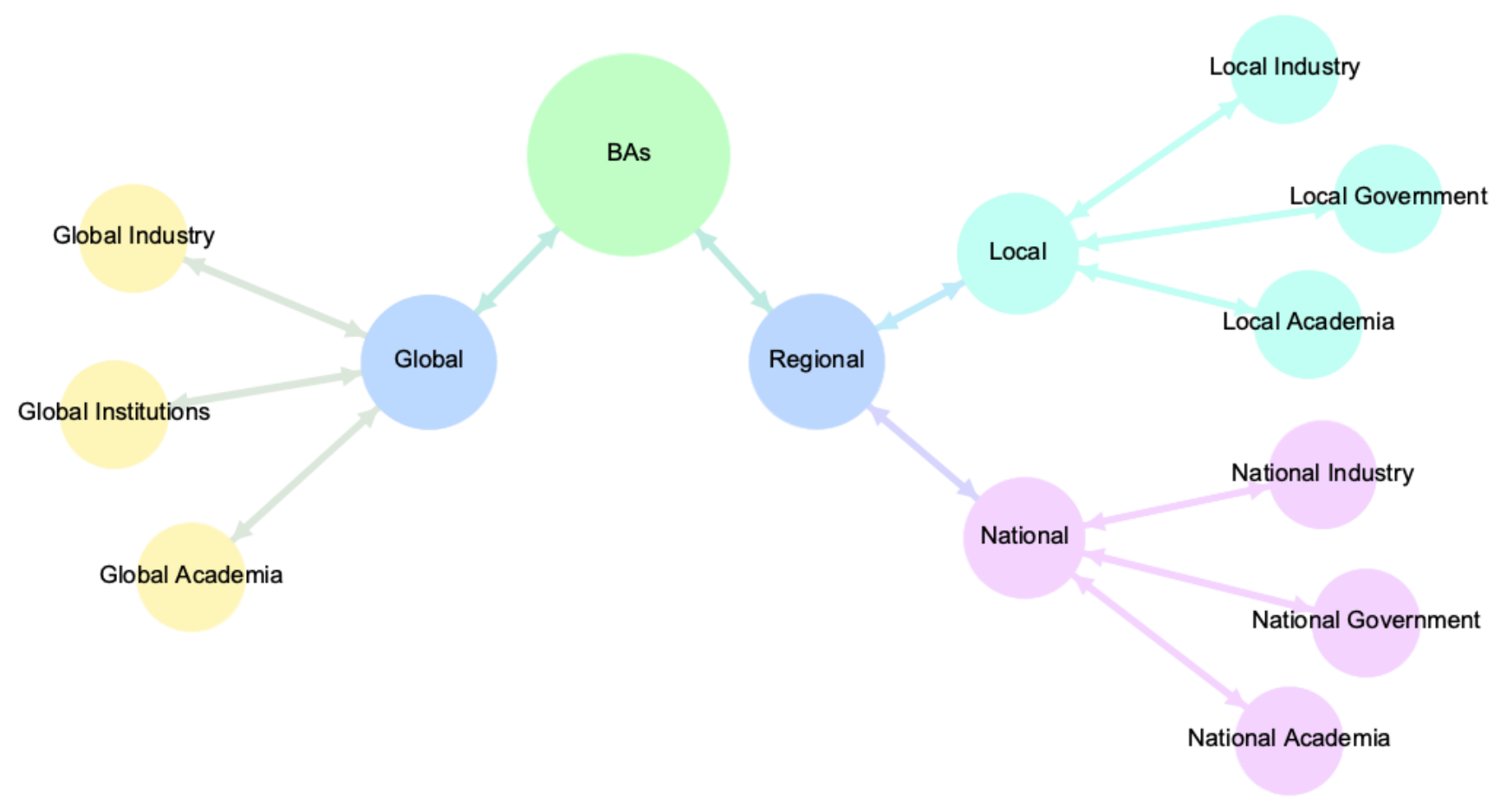

Figure 1. Multi-node knowledge link model.

... using the existing partnership as a gateway to help the various stakeholders achieve greater sustainability outcomes in their SDGs. Through new technology or new collaborations, the existing arrangement could be transformed into a valuable venture. (IS-9)

The BAs in the multi-node knowledge link model highlight the active role universities can play in enhancing the innovative potential of regions by augmenting the capabilities of different stakeholders. The integrated approach linking institutions and corporate partners for the issues related to sustainability influences stakeholders positively in the long run [27]. The BAs-led interactions can help in fulfilling the need for social innovation to realize the goals associated with sustainable development. Social innovation in this context refers to the importance of shared knowledge to enhance the social well-being and quality of life for the community members. Improvements in the social well-being of community members will help in attaining the long-term goals concerning sustainable development. 
The sustainability-oriented public-private partnership framework regulates collaborative interaction among stakeholders from the defined boundaries of sustainable solutions and development. However, the characteristic of public-private partnership in tackling sustainability-oriented issues is evolving towards a more collaborative involvement of diverse stakeholders' perspectives. The BAs in the multi-node knowledge link model plays a central role as an agent of knowledge diffusion that facilitates the knowledge flow in collaborative environments among regional (national and local) and global stakeholders.

\subsection{Outcomes: Knowledge Sharing and Value Creation}

Employing the sustainability-oriented partnership model, the role of BAs has evidently resulted in facilitated knowledge diffusion among stakeholders at the global, national and local levels. It has raised awareness of knowledge gaps, assisted interaction, built capacity, and created relevance for knowledge sharing to address sustainability and creative solutions.

\subsubsection{Awareness of Knowledge Gaps through Inter- and Intra-Cluster Interaction}

The exposure and interactions among stakeholders augmented the understanding of knowledge gaps regarding sustainability at the inter- and intracluster levels, respectively. First, within the intercluster exchange, international students gained an understanding of the differences between theoretical concepts and business and local practices from other clusters. The gap between theoretical knowledge and its application has been widely recognized in earlier studies [28]. One participant mentioned this:

'There were many times I found myself saying "That is what they meant in class...". It was a very hands-on, practice-based project. It tested many of the design philosophies I have studied. The practical experience was priceless.' (IS-1)

Second, the knowledge gap among stakeholders at the intracluster level was highlighted in interviews during the reflection session. The three local stakeholders, including Ricoh Elemex members, Ena City government, and Ena International Exchange Association, were located within Ena City. The feedback shows the awareness of the differences in their respective approaches toward sustainability by the end of the project. The knowledge gap between stakeholders within the same cluster exists even in close geographical proximity [29]. However, they lack social proximity and knowledge sharing. An employee of Ricoh Elemex, who is also part of the forest management committee, explains it this way:

'Through the proposals, I would see what has been missing to reorganise the forest activities to be aligned with our SDGs even though we are "neighbours" in Ena City'. (ELEM-1)

The following statement captures the sentiments of a government representative: 'Even though our city government has known about the Ricoh Elemex and Ricoh Ena Forest located in our city, however we have never communicated or collaborated about sustainability issues until this project. We have learnt a lot about each other.' (ENA-1)

\subsubsection{Effective Communication Outcomes through Interaction}

The BA-led project structure enabled the participants to initiate a communication loop connecting every stakeholder. The process involved knowledge sharing through information sessions, interviews, proposal discussions, and feedback sessions among stakeholders. Through such interactive learning, stakeholders have reduced their cognitive distance and overcome knowledge complementarities [30]. These unique settings provide all stakeholders with essential exposure for enriched interactions.

Stakeholders can have expectations from other groups of stakeholders participating in the same project. International students and regional stakeholders have gained motivation and interest in the exchange of ideas and discussions. One participant stated this:

'From the direct interview with stakeholders (Ricoh HQ and Ricoh Elemex) at the breakout session, I got a clearer impression that environmental conservation and community 
engagement was the top priority. Project representatives were not too worried about financial sustainability.' (IS-3)

The group-initiated activities for research and data collection were dynamic interaction options for stakeholders to collaborate with each other. One participant recalled the following:

'Through the online interaction with stakeholders, I would feel the importance of contributing our expertise. Through the self-initiated fieldwork by our group, I appreciate the data provided during the online session, but the motivation of the forest members has given me additional perspectives to better improve the solutions.' (IS-4)

The interaction platform was surprising for industry and community stakeholders, as they recollected their thoughts in the following statement:

'I was surprised yet amazed with the intense interview with the international students during the online breakout session. Thus, we came together to guide the students for the initiated fieldwork and followed up interviews outside the workshop.' (ELEM-1 and EIEA-1)

\subsubsection{Knowledge Extension through Regionally Focused Proposal}

The analysis showed that after collaboration, stakeholders who represented different clusters extended their knowledge gains arising from the proposal based on Ricoh Ena Forest.

International students have completed their proposals as proof of concepts through workshops. As an extension of the knowledge gained, international students would like to implement the SDGs relevant project and directly contribute toward the development of SDGs in Ricoh Ena Forest. One of the participants mentioned the following:

'Before the course, I had a "BIG WHY" about companies who adopt SDGs in their businesses and business models. Thanks to the workshop, I have gained understanding and comments for my proposal created for Ricoh Ena Forest. If there is an opportunity, I would like to implement our plan into reality through the support of the regional stakeholders.' (IS-10)

The international researcher extended the feedback on the impact of her research to conduct a detailed case analysis of Ricoh Corporation. With the network connection, she would perform qualitative studies to better understand the dilemma and cooperation between different levels of goals and activities within the same organization in sustainability. They explained this as follows:

'After the project, I would like to explore the research to understand the effects of ESG in Ricoh from at the national level to create a used case.' (IR-1)

The collaboration has resulted in knowledge diffusion and motivation for follow-up on knowledge extension by senior managers at the Ricoh Group HQ. Even at the national level, there is a lack of exemplary cases for future learning and discussion. The Ricoh Group HQ representative shared his feedback after the workshop:

'We would continue this collaboration to find solutions for the sustainability strategy of my corporation. I would like to compare case studies between Japan and foreign countries through the international students. We would follow-up to invite the academics for a joint research presentation to share about collaboration of SDGs projects with other institutions at the national level.' (RICOH-1)

\subsubsection{Creation of Shared Values through Global and Regional Knowledge Convergence}

The model empowered the convergence of knowledge for the creation of shared values among all stakeholders. The insights gained from the diverse perspective's learnings can be generalized to create new shared values. This is aligned with the principle of creating shared value as advocated by Porter and Kramer [31] in partnership formation. One participant stated this: 
'I learned a lot about sustainable development projects in companies and the overall externalities and internal issues that made those projects hard to develop. I also learned how both can create value for the companies and the society.' (IS-17)

Ricoh Elemex was able to consider innovative methods for organizing forest activities while considering user benefits. The Ena City government was prompted to reflect on their existing SDGs policies to improve local residents' experience. The following quotation captures these sentiments:

'I could see how our daily activities in the forest could achieve a common goal as we have shared values about the creation of a sustainable environment for all.' (ELEM-1)

The Ena City government expressed their gratitude towards the international students and other stakeholders for their interest and active contribution to improving sustainability by considering the Ricoh Ena Forest, the community in Ena City and beyond. The government representatives stated the following:

'We considered the importance of shared value to be the key towards enabling the city to achieve as a Future SDGs city. This collaboration provides precedence for other engagements beyond members in Ena City. Thanks to the faculty member for bringing us through the learning process.' (ENA-2)

\section{Conclusions}

This study analyzed a case of a sustainability-driven partnership — the SDGs Workshop in Central Japan-to examine the role of academics in the knowledge diffusion process. The findings of this study are as follows.

First, the study examined the role of how BAs facilitate collaborative partnership among stakeholders in addressing sustainability challenges, which extended the existing role of BAs in knowledge diffusion discussed by Atta-Owusu's [8]. We concluded that BAs induced collaborations and facilitated interaction among different groups of stakeholders. Through the multi-node knowledge link model, BAs facilitated knowledge diffusion among global and regional (national and local) stakeholders. BAs provided a formalized sustainability-oriented platform for knowledge diffusion among global participants and regional stakeholders involved in the workshop.

The study conceptualized the diffusion of knowledge and elimination of knowledge gaps among stakeholder networks using the multi-node knowledge link model. The model incorporates the local and national stakeholders, which contributes to the existing BAs literature $[6,13]$ that overlooked the distinctions within the regional stakeholders. The findings suggest that stakeholders of a specific project have a different understanding of the project, its scope, and objectives. Interaction among stakeholders is beneficial in eliminating such inconsistencies; however, the interaction can be sparse, and knowledge can be divergent. Collaborative activities initiated by BAs bring all stakeholders together. Such interaction helps stakeholders realize the difference in perspectives regarding projects and their potential implications. BAs are equipped with a better understanding of theoretical concepts but sometimes lack industry exposure. This interaction can be helpful in exploring the applicability of the theoretical grounds. The industry partners manage collaborative projects using standard procedures or the guidelines given by the regional stakeholders. The situation changes when a project in consideration is not a regular corporate project but a sustainability-oriented public-private partnership project. There are strong motivations for better stakeholder interactions. Primarily, sustainability-oriented projects have recently become part of corporate portfolios. Due to the emerging field and evolving nature of projects, industry partners encourage stakeholder collaboration but lack a structured mechanism. In addition, sustainability-oriented projects influence communities and have a significant personal impact on most stakeholders, and most would like to understand their scope and effects.

Second, the study derived four thematic outcomes that are generated from the BAsdriven knowledge diffusion in the sustainability-driven public-private partnerships. These 
include acknowledging knowledge gaps through multi-stakeholders interactions, communicating effectively through interactive platforms, extending knowledge through regionally focused proposals, and generating shared values through the convergence of global and regional (national and local) knowledge. The thematic outcomes connect with and extend the boundaries of existing work in relation to the effectiveness of stakeholder interactions in collaborative arrangements [29-31].

The research provides a deeper understanding of the role and function of BAs, focusing on a collaborative project in a region with dynamic lenses. Through the findings, three specific roles and functions of BAs were ascertained. First, BAs may bridge the 'knowledge gap' among stakeholders. BAs induce structured interactions that facilitate bridging the gap between different groups and layers of stakeholders. Each group plays a role in a certain capacity under the prearranged guidelines or instructions of the project managers. Big projects involve a variety of stakeholders and synchronous interactions. Distinctive understanding of project objectives among partners and managers is required in gathering everyone on a single platform. Second, BAs stimulate communication by streamlining interactive spaces. The interactive space enables stakeholders to communicate with each other in a supervised and objective-driven environment. The presence of BAs ensures that every participant reaches the minimum level of required understanding through early information sessions. Subsequent discussions focused on achieving the desired targets. Third, BAs foster knowledge sharing. Another significant aspect of knowledge diffusion among partners of a single project is the potential relevance of shared knowledge. Each participant grasped different concepts as per his or her academic background, industry exposure, and cultural context. The interaction assists global participants in considering the applicability of shared knowledge in their own surroundings. This generalization will help expand the knowledge flow in all directions. Every stakeholder discovers and adapts accordingly. The possibility of imitating projects under similar conditions increases multiple times. Thus, we conclude that the research has theoretically contributed towards the understanding of bridging academic and discussion of societal impact of universities on regional/national innovation ecosystems from the academic perspectives.

This study has implications for academic institutions, industry partners, and policymakers that addresses the theme of sustainability. Academic institutions such as universities can play a critical role in developing the role of BAs to moderate stakeholder interactions. These interactions not only enhance the understanding of their students and faculty members but also improve the effectiveness of regional collaborative projects. Industrial partners should engage local and international stakeholders extensively to overcome inertia in order to develop sustainable solutions. These collaborative arrangements enable stakeholders, including local governments, to actively engage with other partners. Governments can utilize this opportunity to interact with academic and industry partners to understand their perspectives on sustainability-related issues. This is the first step in formulating and realizing shared policy goals. Thus, the study highlighted a use case of a successful public-private partnership in the context of a sustainability driven project that overcomes the strategic shortcomings commonly observed in other public-private partnerships [18] (Nieth, 2019).

This study had several limitations. First, the study applied a single case study analysis of a public-private partnership which limits research validity. Further research could adopt case comparisons to study two or more partnerships based on regional projects to improve the validity of the multi-node knowledge link model. Next, the subject of sustainability may be too broad for exploration. Thus, future research could explore specific themes in sustainability. For example, the 'reuse and sustainability of wood' is the focal point for the research. Third, there was an over-reliance on local clusters with extended stakeholders than on other clusters, which resulted in a bias in the knowledge diffusion outcomes. Thus, future studies may employ additional organizations to better represent the other clusters, such as involving the national government or sustainability association in the national cluster. In addition, future research could attempt to quantify and empirically 
analyze the potential impacts of universities on regional/national innovation ecosystems. Future work would provide balanced, in-depth knowledge at every layer of the multi-node knowledge-linked model explored in this study.

Author Contributions: Conceptualization, M.M.H. and H.C.G.; methodology, M.M.H. and H.C.G.; validation, F.; formal analysis M.M.H. and F.; investigation, M.M.H. and H.C.G.; resources, F.; data curation, M.M.H. and F.; writing-original, M.M.H., H.C.G. and F.; draft preparation, M.M.H. and H.C.G.; writing-review and editing, M.M.H., H.C.G. and F.; project administration, H.C.G. All authors have read and agreed to the published version of the manuscript.

Funding: This research received no external funding.

Informed Consent Statement: Informed consent was obtained from all subjects involved in the study.

Data Availability Statement: Not applicable.

Acknowledgments: Special acknowledgement to Ricoh Corporation, Ena City International Exchange Association for the cooperation throughout the research implementation and data collection phase, and NUCB Business School for administrative and technical support.

Conflicts of Interest: The authors declare no conflict of interest.

\section{Appendix A}

Table A1. Timeline for SDGs workshop activities with different stakeholders.

\begin{tabular}{ccc}
\hline Stage & Date (2020-2021) & Activities \\
\hline \multirow{3}{*}{ Planning } & $11 / 03 / 2020$ & SDGs workshop internal Committee Meeting \\
& $20 / 03 / 2020$ & 1st Fieldwork at Ricoh Ena Forest \\
& $29 / 07 / 2020$ & 1st SDGs workshop Committee meeting \\
$22 / 08 / 2020$ & 2nd SDGs workshop Committee Meeting \\
$24 / 09 / 2020$ & 2nd Fieldwork at Ricoh Ena Forest \\
& $14 / 10 / 2020$ & 3rd SDGs workshop Committee meeting \\
\hline \multirow{3}{*}{ Intervention } & $15 / 10 / 2020$ & \\
& $12 / 11 / 2020$ & \\
& $10 / 12 / 2020$ & SDGs workshop Virtual Live Sessions \\
Reflection & $23 / 12 / 2020$ & \\
& $24 / 12 / 2020$ & SDGs debriefing session 1 (Ena City Hall and EIEA Office) \\
& $14 / 1 / 2021$ & SDGs debriefing session 2 (Student groups) \\
\end{tabular}

Table A2. SDGs workshop stakeholders.

\begin{tabular}{ccccc}
\hline No & Cluster & Country & Category & Index \\
\hline 1 & Global & USA & International Student & IS-1 \\
2 & Global & France & International Student & IS-2 \\
3 & Global & Germany & International Student & IS-3 \\
4 & Global & Ghana & International Student & IS-4 \\
5 & Global & Germany & International Student & IS-5 \\
6 & Global & USA & International Student & IS-6 \\
7 & Global & Philippines & International Student & IS-7 \\
8 & Global & India & International Student & IS-8 \\
9 & Global & India & International Student & IS-9 \\
10 & Global & Vietnam & International Student & IS-10 \\
11 & Global & Chile & International Student & IS-11 \\
12 & Global & Vietnam & International Student & IS-12 \\
13 & Global & Indonesia & International Student & IS-13 \\
14 & Global & Gambia & International Student & IS-14 \\
15 & Global & Japan & International Student & IS-15 \\
16 & Global & South Africa & International Student & IS-16 \\
\hline
\end{tabular}


Table A2. Cont.

\begin{tabular}{ccccc}
\hline No & Cluster & Country & Category & Index \\
\hline 17 & Global & Japan & International Student & IS-17 \\
18 & Global & Saudi Arabia & International Researcher & IR-1 \\
19 & National & Japan & Ricoh Group HQ & RICOH-1 \\
20 & National & Japan & Ricoh Group HQ & RICOH-2 \\
21 & Local & Japan & Ricoh Elemex Employee & ELEM-1 \\
22 & Local & Japan & Ricoh Elemex Employee & ELEM-2 \\
23 & Local & Japan & Ena City Government & ENA-1 \\
24 & Local & Japan & Ena City Government & ENA-2 \\
& Local & Japan & Ena City Government & ENA-3 \\
25 & Local & Japan & Ena International Exchange & EIEA-1 \\
26 & & & Association & \\
\hline
\end{tabular}

\section{References}

1. $\quad$ Brundtland, G.H.; WCED. Our Common Future; Oxford University Press: Oxford, UK, 1987.

2. Vargas, V.R.; Lawthom, R.; Prowse, A.; Randles, S.; Tzoulas, K. Sustainable development stakeholder networks for organisational change in higher education institutions: A case study from the UK. J. Clean. Prod. 2019, 208, 470-478. [CrossRef]

3. Dupont, L.; Morel, L.; Guidat, C. Innovative public-private partnership to support Smart City: The case of "Chaire REVES". J. Strategy Manag. 2015, 8, 245-265. [CrossRef]

4. Hagen, R. Globalization, university transformation and economic regeneration: A UK case study of public/private sector partnership. Int. J. Public Sect. Manag. 2002, 15, 204-218. [CrossRef]

5. Leydesdorff, L. The knowledge-based economy and the triple helix model. Annu. Rev. Inf. Sci. Technol. 2010, 44, 365-417. [CrossRef]

6. Trippl, M. Scientific mobility and knowledge transfer at the interregional and intraregional level. Reg. Stud. 2013, 47, 1653-1667. [CrossRef]

7. Chubu Bureau of Economy, Trade and Industry. Outline of the Chubu Region; Chubu Bureau of Economy, Trade and Industry: Nagoya, Japan, 2019. Available online: https:/ / www.chubu.meti.go.jp/english/ (accessed on 15 December 2021).

8. Atta-Owusu, K. Oasis in the desert? Bridging academics' collaboration activities as a conduit for global knowledge flows to peripheral regions. Reg. Stud. Reg. Sci. 2019, 6, 265-280. [CrossRef]

9. Ruhanen, L.; Cooper, C. Applying a Knowledge Management Framework to Tourism Research. Tour. Recreat. Res. 2004, 29 , 83-87. [CrossRef]

10. Cai, Y.; Ferrer, B.R.; Lastra, J.L.M. Building university-industry co-innovation Networks in transnational innovation ecosystems: Towards a transdisciplinary approach of integrating social sciences and artificial intelligence. Sustainability 2019, 11, 4633. [CrossRef]

11. Bathelt, H.; Cohendet, P. The creation of knowledge: Local building, global accessing and economic development-Toward an agenda. J. Econ. Geogr. 2014, 14, 869-882. [CrossRef]

12. Lattu, A.; Cai, Y. Tensions in the sustainability of higher education: The case of Finnish universities. Sustainability 2020, $12,1941$. [CrossRef]

13. Benneworth, P.; Fitjar, R.D. Contextualizing the role of universities to regional development: Introduction to the special issue. Reg. Stud. Reg. Sci. 2019, 6, 331-338. [CrossRef]

14. UNESCO. Aichi-Nagoya Declaration on Education for Sustainable Development; UNESCO: Paris, France, 2014.

15. Cheng, Z.; Wang, H.; Xiong, W.; Zhu, D.; Cheng, L. Public-private partnership as a driver of sustainable development: Toward a conceptual framework of sustainability-oriented PPP. Environ. Dev. Sustain. 2021, 23, 1043-1063. [CrossRef]

16. Ahmed, S.A.; Ali, S.M. People as partners: Facilitating people's participation in public-private partnerships for solid waste management. Habitat Int. 2006, 30, 781-796. [CrossRef]

17. Choi, G.; Jin, T.; Jeong, Y.; Lee, S.K. Evolution of Partnerships for Sustainable Development: The Case of P4G. Sustainability 2020 12, 6485. [CrossRef]

18. Nieth, L. Understanding the strategic 'black hole' in regional innovation coalitions: Reflections from the Twente region, eastern Netherlands. Reg. Stud. Reg. Sci. 2019, 6, 203-216. [CrossRef]

19. Galvão, A.R.; Marques, C.S.E.; Ferreira, J.J.; Braga, V. Stakeholders' role in entrepreneurship education and training programmes with impacts on regional development. J. Rural Stud. 2020, 74, 169-179. [CrossRef]

20. Yin, R.K. Case Study Research and Applications: Design and Methods, 6th ed.; SAGE Publications: Thousand Oaks, CA, USA, 2018.

21. Andon, P. Accounting-Related research in PPPs/PFIs: Present contributions and future opportunities. Account. Audit. Account. J. 2012, 25, 876-924. [CrossRef] 
22. Chung, D. Risks, challenges and value for money of Public-Private partnerships. Financ. Account. Manag. 2016, 32, 448-468. [CrossRef]

23. Braun, V.; Clarke, V. Using thematic analysis in psychology. Qual. Res. Psychol. 2006, 3, 77-101. [CrossRef]

24. Ricoh. Biodiversity: Social Responsibility Activities-Ena Forest Projects (Conservation of Company-Owned Forest). 2021. Available online: https:/ / www.ricoh.com/sustainability/environment/biodiversity/contribution/ena_forest (accessed on 15 December 2021).

25. Stone, D. Introduction: Global knowledge and advocacy networks. Glob. Netw. 2002, 2, 1-12. [CrossRef]

26. Fischer, F. Citizens, Experts, and the Environment: The Politics of Local Knowledge; Duke University Press: Durham, NC, USA, 2000.

27. Morawska-Jancelewicz, J. The Role of Universities in Social Innovation Within Quadruple/Quintuple Helix Model: Practical Implications from Polish Experience. J. Knowl. Econ. 2021, 20, 1-42. [CrossRef]

28. Viswanath, K.; Finnegan, J.R. The Knowledge Gap Hypothesis: Twenty-Five Years Later. Ann. Int. Commun. Assoc. 1996, 19, 187-228. [CrossRef]

29. Boschma, R. Proximity and innovation. A critical assessment. Reg. Stud. 2005, 39, 61-74. [CrossRef]

30. Cowan, R.; Jonard, N.; Zimmermann, J.B. Bilateral collaboration and the emergence of innovation networks. Manag. Sci. 2007, 53, 1051-1067. [CrossRef]

31. Porter, M.E.; Kramer, M.R. The Big Idea: Creating Shared Value. How to Reinvent Capitalism—and Unleash a Wave of Innovation and Growth. Harv. Bus. Rev. 2011, 89, 62-77. 